THE EFFECT OF ACUTE ALCOHOL INTOXICATION ON RISK ATTITUDE

A Dissertation
presented to
the Faculty of the Graduate School
at the University of Missouri-Columbia,
In Partial Fulfillment
of the Requirements for the
Degree of Doctor of Philosophy
KAYLEIGH MCCARTY
Dr. Denis McCarthy, Dissertation Supervisor
JULY 2021


The undersigned, appointed by the dean of the Graduate School, have examined the dissertation entitled

\section{THE EFFECT OF ACUTE ALCOHOL INTOXICATION ON RISK ATTITUDE}

presented by Kayleigh McCarty, a candidate for the degree of Doctor of Philosophy, and hereby certify that, in their opinion, it is worthy of acceptance.

Professor Denis McCarthy

Professor Clintin Davis-Stober

Professor Timothy Trull

Professor Bruce Bartholow

Professor Matthew Martens 


\section{DEDICATION}

I am grateful for all my friends and loved ones who have supported me during my graduate training. I would especially like to thank my mom and siblings for their encouragement throughout my life. I also feel very lucky for the friends I have made during graduate school. Finally, and most importantly, I would like to thank my partner, Spencer, and our pets (Hoshi, Joseph, Josie, Leilah, Mirri, and Sammi). This past year especially would not have been possible without you. 


\section{ACKNOWLEDGEMENTS}

I would like to thank my advisor, Dr. Denis McCarthy, for his guidance and mentorship throughout my long graduate journey. I would also like to acknowledge Dr. Clintin Davis-Stober for serving as a secondary advisor and mentor. I am grateful for the other members of my dissertation committee, Dr. Bruce Bartholow. Dr. Matthew Martens, and Dr. Timothy Trull. Thank you all for your thoughtful feedback. Finally, I would like to thank my labmates, Laura Hatz and Olivia Warner, for their help and support with this project.

My original planned dissertation was disrupted by the COVID-19 pandemic, as data collection had to be discontinued. I appreciate my committee's flexibility in allowing me to alter my plans so I could complete my degree on time. The current project used data that was collected as part of a series of studies about the effects of acute alcohol intoxication on various constructs that may be associated with alcohol-impaired driving and other risktaking behaviors. While it was not intended to be a dissertation at the time it was collected, I am grateful to have had the opportunity to use this data for my dissertation project. I would also like to acknowledge the project coordinators and undergraduate research assistants who contributed to data collection. 


\section{TABLE OF CONTENTS}

ACKNOWLEDGEMENTS ...........................................................

LISTS OF FIGURES..........................................................

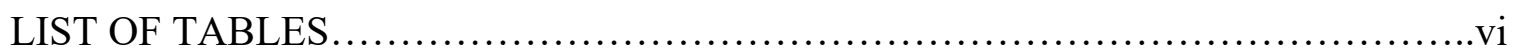

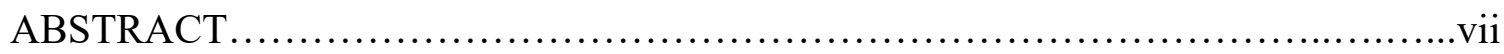

Chapter

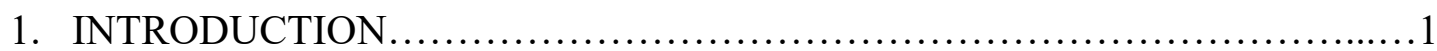

Decision Making under Risk

Measuring Risk Attitude and Risk Taking Propensity

Decision Making and Problematic Alcohol Use

Reward Sensitivity and Problematic Alcohol Use

Effect of Acute Alcohol Intoxication

Current Study

2. METHOD.

Participants and Eligibility

Measures

Procedure

Analytic Strategy

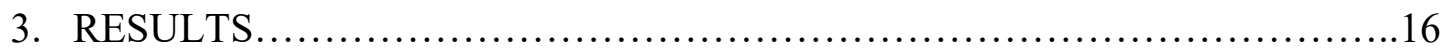

Global Risk Attitude Classification

Comparison of Global Risk Attitude Classification in the Alcohol and Placebo

Conditions

Gamble Specific Risk Attitude Classification 
Comparison of Gamble Specific Risk Attitude Classification in the Alcohol and Placebo Conditions

Risk Attitude and Alcohol Involvement

Risk Attitude and Risk Taking Behaviors

Risk Attitude and Behavioral Economics

Risk Attitude and Expectancies

Risk Attitude and Personality Traits

Stability of Risk Attitude

4. DISCUSSION

APPENDIX

1. FIGURES.

2. TABLES.

REFERENCES. 44

VITA...... .56 


\section{LIST OF FIGURES}

1. Example Gamble from Decision Making Task...................................29 


\section{LIST OF TABLES}

1. Global Risk Attitude Classifications in Alcohol and Placebo Conditions..........30

2. Crosstabulation for Global Risk Attitude in Alcohol and Placebo Conditions....31

3. Risk Seeking vs. Not Risk Seeking Classifications......................... 32

4. Gamble Specific Risk Attitude Classifications in Alcohol and Placebo

Conditions.

5. Crosstabulation for Gamble Specific Risk Attitude (Gains) in Alcohol and

Placebo Condition

6. Crosstabulation for Gamble Specific Risk Attitude (Losses) in Alcohol and

Placebo Condition.

7. Crosstabulation for Gamble Specific Risk Attitude (Mixed) in Alcohol and Placebo Condition.

8. Bayes Factor Results from Comparisons of Risk Seeking to Not Risk Seeking Classifications for Alcohol Involvement.

9. Bayes Factor Results from Comparisons of Risk Seeking to Not Risk Seeking Classifications for Risk Taking Behaviors

10. Bayes Factor Results from Comparisons of Risk Seeking to Not Risk Seeking Classifications for Behavioral Economics .39

11. Bayes Factor Results from Comparisons of Risk Seeking to Not Risk Seeking Classifications for Expectancies.

12. Bayes Factor Results from Comparisons of Risk Seeking to Not Risk Seeking Classifications for Personality Traits

13. Bayes Factor Results from Risk Attitude Stability. 42 


\title{
THE EFFECT OF ACUTE ALCOHOL INTOXICATION ON RISK ATTITUDE
}

\author{
Kayleigh McCarty \\ Dr. Denis McCarthy, Dissertation Supervisor
}

\begin{abstract}
There is a strong relationship between engaging in risk taking behaviors, or behaviors with a high probability of negative and undesirable consequences, and the use of alcohol and other substances of abuse. Mounting evidence suggests that dysfunctional decision making contributes to the development and maintenance of addiction and related behaviors. This study explored the effects of acute alcohol intoxication on decision making under risk. Regular drinkers were recruited for a within subjects, placebo controlled, alcohol administration study. They completed a decision-making task at peak alcohol intoxication and at a time matched assessment in a placebo condition, as well as several baseline measures. The aim of this study was to examine whether alcohol intoxication impacts risk attitude. The associations between risk attitude and related personality traits, problematic alcohol use, and alcohol related risk-taking behaviors were also tested. The results of the study suggest that intoxicated risk attitude, and not risk attitude in the placebo condition, is associated with indices of alcohol consumption and to a lesser extent, alcohol consequences. Alcohol intoxication did not significantly impact risk attitude classification. Risk attitude was not associated with impulsive personality traits, alcohol expectancies, or risk-taking behaviors. While risk attitude may have utility for identifying those who are at risk for alcohol problems, tasks designed to assess behavior specific decision processes may be useful for understanding risky patterns of decision making.
\end{abstract}




\section{Introduction}

There is a strong relationship between engaging in risk taking behaviors, or behaviors with a high probability of negative and undesirable consequences, and the use of alcohol and other substances of abuse (Lejuez et al., 2002). This association is complex, as substance use can be characterized as a risk-taking behavior and also increase the likelihood of other risk-taking behaviors. For instance, heavy episodic drinking involves significant risk for negative health outcomes (SAMHSA, 2015) and increases secondary risk taking (e.g., drinking and driving, risky sexual behaviors; Hendershot et al., 2009; Voas et al., 2012).

Mounting evidence suggests that dysfunctional decision making contributes to the development and maintenance of addiction and related behaviors (Koffarnus \& Kaplan, 2018; Verdejo-Garcia et al., 2018). This study was designed to improve our understanding of the effect of alcohol intoxication on the decision-making processes associated alcoholrelated risk taking. A gamble task based on an iteration of Luce's (2010) mathematical model of decision making under risk (Davis-Stober \& Brown, 2013) allowed for the assessment of participants' attitude toward risk under different conditions (e.g., winning/losing money, high stakes/low stakes). This task was administered under acute alcohol intoxication and under placebo to test alcohol-induced changes in risk attitude within subjects. Further, the associations between risk attitude and alcohol-related behaviors were examined.

\section{Decision Making under Risk.}

Decisions with ambiguous outcomes can be classified into two categories: decision under ignorance (or uncertainty) and decision under risk (Peterson, 2009). Decision making 
under ignorance involves situations in which it is nonsensical to assign probabilities to possible outcomes (Peterson, 2009). For instance, the doctor performing the first ever human heart transplant would have been unable to assign probabilities to possible outcomes of the surgery (i.e., life or death). In contrast, decision making under risk refers to the process of making choices when it is possible to assign probabilities to possible outcomes (e.g., fair coin flip, gambling; Kahneman \& Tversky, 1979). This model does not require that the exact probabilities of outcomes are "known" or immediately accessible, but rather requires that individuals have access to necessary information to determine the probability after performing a series of possibly complex calculations (Peterson, 2009). For instance, a person playing roulette may not be able to state the expected payout of their bet, but this number could be calculated. Similarly, a doctor performing a heart transplant in the present day can provide patients with the probability of a successful surgery based on the success of previous procedures.

An individual's risk attitude, or preferred level of risk, is commonly measured by the choices made during gamble tasks designed to model decision making under risk. These gamble tasks typically involve a choice between two monetary gambles or outcomes (e.g., choosing between " $50 / 50$ chance of winning $\$ 14$ or $\$ 4$ " and " $50 / 50$ chance of winning $\$ 11$ or $\$ 7 ”)$. Classic models of risk attitude classified individuals as risk seeking, risk averse, or risk neutral (Kahneman \& Tversky, 1979; Luce, 2010). The mathematical modeling of risk attitude has been further developed to allow risk attitude to vary as a function of the decision-making environment (Davis-Stober \& Brown, 2013). For instance, individuals who are risk seeking for loss outcomes and risk averse for gain outcomes (the reflection effect) is not well described by a single risk attitude classification (Kahneman \& Tversky, 
1979), but can be described well by a model allowing an individual's risk attitude to vary based on the characteristics of the decision being made.

\section{Measuring Risk Attitude and Risk-Taking Propensity.}

Several behavioral tasks have been developed to measure risk taking propensity. For instance, the Iowa Gambling Task (Bechara et al., 1994) and the Balloon Analog Risk Task (BART; Lejuez et al., 2002), were designed to measure risk taking in a way that parallels decision making in real-world situations. These measures have their merits, as performance on these tasks is associated with real-world risk-taking behavior (Aklin et al., 2005; Lejuez et al., 2004; MacPherson et al., 2010) and personality traits related to risk taking (e.g., reward and punishment sensitivity; O'Doherty et al., 2001). However, these tasks model a single dimension of risk, with performance on the task indicative of level of risk taking, precluding examination of contextual influences on risk taking.

One of the innovations of Prospect Theory (Kahneman \& Tversky, 1979) was the notion that an individual's risk attitude can vary across context (e.g., risk averse for gains but risk seeking for losses), consistent with the observation that individuals predisposed to risk taking do not engage in all varieties of risk-taking behaviors or do so under all circumstances. In the current study, risk attitude was measured with a gamble task using a recent refinement to Luce's mathematical model of decision making under risk (DavisStober \& Brown, 2013). Participants were asked to indicate their preference in a series of gamble pairs: one risky, with high variance between outcomes, and one safe, with low variance, but both choices had the same expected value (see Figure 1). Bayesian methods were used to estimate participants' risk attitude. This modeling approach allowed for examination of how risk attitude changes (1) in response to different gamble types and (2) 
under acute alcohol intoxication, offering insight into the value participants place on risky and safe decisions in different contexts. Assessment of risk attitude under different conditions may provide unique information on the factors contributing to risk taking that could not be obtained from unidimensional or self-report measures. Clarifying contextual influences on risk attitude could ultimately have implications for our understanding of alcohol-related behaviors with varying "gains" and "losses" (e.g., aggression, risky sex, drinking and driving).

\section{Decision Making and Problematic Alcohol Use.}

One of the most studied elements of decision making in relation to substance use is delay discounting. Delay discounting is defined as discounting the value of delayed rewards in favor of rewards available without delay (Koffarnus \& Kaplan, 2018). Excessive delay discounting is a consistent marker of addiction across a range of substances and indicates a tendency toward short-sightedness in decision making processes (Amlung et al., 2017; Coffey et al., 2003; Heil et al., 2006; Hoffman et al., 2006; Johnson et al., 2007; Kirby et al., 1998; Mackillop et al., 2010; Petry et al., 1998; Washio et al., 2011). Greater preference for immediate rewards is also associated with engaging in alcohol related risk-taking behaviors (e.g., alcohol impaired driving; McCarthy et al., 2012; Rossow, 2008).

Behavioral economic demand is an adaptation of standard economic demand, quantifying the association between the cost of a commodity and consumption of that commodity (Koffarnus \& Kaplan, 2018). In the field of addiction, behavioral economic demand serves as an index of one's motivation to consume substances (Aston et al., 2015; Bruner \& Johnston, 2014; Christensen et al., 2008; Gray \& MacKillop, 2015; Johnson \& 
Johnson, 2014; MacKillop et al., 2008; Murphy \& MacKillop, 2006; Reed et al., 2016). Indices of behavioral economic demand for alcohol are associated measures of consumption (MacKillop et al., 2009), alcohol use disorder severity (MacKillop et al., 2010), and alcohol related risk-taking behaviors (Amlung et al., 2016; Teeters \& Murphy 2015; Teeters et al., 2014).

Risk attitude has primarily been utilized as a predictor of risk-taking behaviors in the fields of economics and finance (Fellner \& Maciejovsky, 2002). Risk attitude has only rarely been applied to health-related decisions. For example, risk aversion was found to be negatively associated with seatbelt non-use, problem drinking, and smoking (Szrek et al., 2012). Previous work by this writer validated risk attitude as a predictor of alcohol problems and impulsivity in a sample of undergraduate students (McCarty, 2016). Results from this study suggested that individuals classified as risk seeking did not consume alcohol at higher rates but did experience more alcohol-related problems, relative to those classified as risk averse. Risk seeking individuals also scored higher on self-report measures of impulsivity and endorsed more positive alcohol outcome expectancies.

\section{Reward Sensitivity and Problematic Alcohol Use.}

Reward hypersensitivity is often considered a defining characteristic of individuals with substance use problems and other risk-taking behaviors (Corr, 2008; Franken et al., 2006; Gray, 1987; Johnson et al., 2003). Reward hypersensitivity is attributed to an overactivation of a behavioral approach system that leads to an attentional bias toward reward cues (Ávila \& Parcet, 2002; Patterson \& Newman, 1993). Individuals who are hypersensitive to rewards often engage in risk taking behaviors, such as substance use, for their potential rewards, despite the likelihood of costly negative outcomes. 
Several theoretical models have been developed to delineate the mechanisms by which reward sensitivity might lead to risk taking behaviors. The acquired preparedness model posits that reward sensitivity can bias learning processes, such that certain behaviors are perceived as more rewarding than others (McCarthy et al., 2001a,b; Smith \& Anderson, 2001). As a result, they form more positive and less negative expectancies for the outcomes of the behavior, which may eventually lead to problematic outcomes (Smith \& Anderson, 2001). This model has substantial support and has been successfully demonstrated longitudinally and with other substances of abuse (e.g., tobacco and cannabis; Corbin et al., 2011; Doran et al., 2013; Hayaki et al., 2011; Settles et al., 2010). Risk attitude may similarly function to bias one's learning by enhancing the reinforcement received from risk taking behaviors. This study aimed to test whether risk attitude, particularly risk attitude under alcohol intoxication, is associated with increased positive expectancies about alcohol and alcohol-related problems. Similarly, this study tested the associations between risk attitude and self-report measures of reward sensitivity and impulsivity.

\section{Effect of Acute Alcohol Intoxication.}

Alcohol intoxication is thought to increase the likelihood of experiencing negative consequences and promote excessive alcohol consumption, yet laboratory studies on the effect of acute alcohol intoxication on decision making have yielded inconclusive results. For delay discounting, some studies suggest that alcohol intoxication decreases rates of delay discounting, suggesting more cautious decision making when intoxicated (Ortner et al., 2003). Most studies report no significant effect of alcohol intoxication on rates of delay discounting (Adams et al., 2016; Bidwell et al., 2013; Johnson et al., 2016; Weafer \& Fillmore, 2016; Wray et al., 2015). Other studies suggest that that the effects of alcohol 
intoxication may be dose dependent, such that higher rates of delay discounting are only observed at higher doses of alcohol consumption (Reynolds et al., 2006). Alcohol intoxication may also affect some elements of perceptual decision making, particularly rates of information processing (van Ravenzwaajj et al., 2012). In contrast, alcohol consumption appears to leave rational decision making intact (Davis-Stober et al., 2019).

Studies on behavioral risk taking have similarly yielded mixed results. One study suggested that alcohol consumption increases risk taking as measured by the BART (Rose et al., 2013), but others have documented no significant effect of alcohol intoxication on performance on this measure (Erskine-Shaw et al., 2017; Peacock et al., 2013; Reynolds et al., 2006). One study also documented the effect of alcohol intoxication on demand for alcohol, suggesting that acute intoxication increases indices of demand relative to the placebo and control conditions (Amlung et al., 2015). Studies on sexual decision making suggest that alcohol intoxication promotes riskier sexual intentions (Davis et al., 2007).

Despite the mixed findings on the effect of alcohol intoxication on decision making, there is evidence documenting the utility of intoxicated assessments in predicting alcohol related behaviors. Rose and colleagues (2014) found that risk taking on the BART while intoxicated predicted alcohol consumption, and this pattern was not observed in a placebo condition. Similarly, intoxicated alcohol demand was associated with intoxicated reports of craving (Amlung et al., 2015). Several studies have documented the effects of alcohol intoxication on decisions related to alcohol-impaired driving. Perceived danger of alcoholimpaired driving measured while intoxicated was associated with increased willingness to drive, as well as higher rates of past alcohol-impaired driving (Morris et al., 2015). Ratings of perceived danger may also demonstrate acute tolerance, such that driving is rated as less 
dangerous on the descending limb of the BrAC curve, relative to the ascending limb (Amlung et al., 2014; Morris et al., 2015). More recent studies have suggested that participants were more willing to drive longer distances when intoxicated on the descending limb, relative to the ascending limb (Motschman et al., 2020). Of note, this pattern was not evident in a placebo condition.

\section{Current Study.}

This study explored the effects of acute alcohol intoxication on decision making under risk. Regular drinkers were recruited for a within subjects, placebo controlled, alcohol administration study. They completed a decision-making task at peak alcohol intoxication and at a time matched assessment in a placebo condition, as well as several baseline measures. The aim of this study was to examine whether alcohol intoxication impacts risk attitude. We hypothesized that alcohol intoxication would influence participants to become more risk seeking. The associations between risk attitude and related personality traits, problematic alcohol use, and alcohol related risk-taking behaviors were also tested. We hypothesized risk seeking individuals would report higher alcohol consumption, greater frequency of risk-taking behavior, and score higher on measures of related personality traits, relative to those who were not risk seeking. Further, we hypothesized that the associations between risk attitude and alcohol involvement, risk taking behaviors, and personality traits would only be present when risk attitude was assessed under alcohol intoxication. We did not hypothesize associations between risk attitude assessed in the placebo condition and relevant outcome variables. 


\section{Method}

Participants and Eligibility. A community sample of regular drinkers was recruited from Columbia, MO and its surrounding area. Participants were required to be between the ages of 21 and 35 and report drinking five or more drinks on at least one occasion in the past six months. Exclusion criteria included pregnancy or nursing, body mass index (BMI) greater than 30, a psychiatric condition or substance use disorder, and medical conditions and medication use with which alcohol use is contraindicated.

A total of 57 participants were recruited. Of these, 10 participants were lost to follow up, and 2 participants had missing data due to computer error. The final sample was 45 participants $(62.2 \%$ men) between the ages of 21 and 27 (mean age $=22.1$ years, $\mathrm{SD}=$ 1.53). Participants primarily identified as white $(n=39,86.7 \%)$, with three identifying as Black/African American (6.7\%), one as Asian (2.2\%), and two as Biracial or Multiracial (4.4\%). Most participants identified as non-Hispanic (93.3\%).

\section{Measures}

\section{Demographics.}

Demographic information, including, age, race, ethnicity, and sex was collected from a self-report questionnaire.

\section{Drinking behaviors.}

Past-year drinking habits were assessed using the items recommended by the NIAAA Task Force (2005). Specifically, the items assessing past-year alcohol quantity, frequency, and binge drinking frequency were used.

\section{Alcohol Consequences.}


The Young Adult Alcohol Consequences Questionnaire (YAACQ; Read et al., 2006) was used to assess alcohol consequences. Participants responded to 48 items with "yes" or "no," indicating whether they had experienced each consequence in the past year. This questionnaire has eight subscales: social/interpersonal, impaired control, selfperception, self-care, risky behaviors, academic/occupational, physiological dependence, and blackout drinking.

\section{Outcome Expectancies and Other Attitudes.}

The Comprehensive Effects of Alcohol (CEOA; Fromme et al., 1993) was used to assess alcohol expectancies. This measure includes 41 items that have been found to load on seven correlated factors: sociability, tension reduction, liquid courage, sexuality, cognitive and behavioral impairment, risk and aggression, and self-perception. Participants responded to each item using a 4-point Likert scale ranging from disagree to agree. The expected benefits and risks components of the Cognitive Appraisal of Risky EventsRevised (CARE-R; Katz et al., 2000) were used to assess cognitive appraisal of risks and benefits associated with risk-taking behaviors (e.g., drug use, risky sexual behavior). Participants responded to each item on a 7-point Likert scale. Finally, participants indicated their perceived safe limit for alcohol impaired driving by specifying the number of drinks they believed they could consume and still drive safely (Amlung et al., 2016).

\section{Behavior Economics.}

The Monetary Choice Questionnaire (MCQ; Kirby et al., 1999) was used to assess delay discounting. The MCQ is composed of 27 items, and each item involves a choice between a smaller, immediate reward and a larger reward that would be received after a specified amount of time (e.g., "would you rather have $\$ 55$ today or $\$ 75$ in 61 days?"). The 
Alcohol Purchase Task (Murphy \& MacKillop, 2006) was used to assess alcohol demand. In this measure, participants reported how many drinks they would purchase at various price points in a hypothetical drinking situation.

\section{Impulsive Personality Traits.}

The UPPS-P (Lynam et al., 2007) was used to assess impulsivity-like traits. The UPPS-P is a 58-item questionnaire that measures negative urgency, lack of perseverance, lack of planning, sensation seeking, and positive urgency. Participants respond to each item using a four-point Likert scale ranging from agree strongly to disagree strongly. The Sensitivity to Punishment and Reward Questionnaire- Revised and Clarified (Connor et al., 2018) was used to assess sensitivity to reward and sensitivity to punishment. This scale is 20 items with five-point Likert scale response options ranging from very untrue to very true.

\section{Risk Taking Behaviors.}

The Cognitive Appraisal of Risky Events- Revised (CARE-R; Katz et al., 2000) was used to assess past frequency of risk-taking behaviors (e.g., drug use, risky sexual behavior). Participants responded to each item on a 7-point Likert scale. Alcohol impaired driving was assessed with a question asking participants to indicate the number of times they have driven in the past year after consuming three alcoholic beverages in two hours.

\section{Breath alcohol concentration.}

Breath alcohol concentration (BrAC) was collected using a FST Alco-Sensor (Intoximeters, Inc.; St. Louis, MO).

Decision Making Task (Davis-Stober \& Brown, 2013). 
Participants were presented with a series of hypothetical paired gambles, and they were asked to indicate their preference or indifference for each gamble pair. Within each pair, one gamble contained two equally likely choices that have a larger variance (e.g., $50 / 50$ chance of winning $\$ 15$ or $\$ 7$ ), while the other gamble contained two equally likely choices with a smaller variance (e.g., $50 / 50$ chance of winning $\$ 10$ or $\$ 12$ ). Both gambles had the same expected value, but the gamble with the larger variance was the "risky" choice, and the gamble with the smaller variance was considered to be the "safe" choice. The gambles varied on the magnitude of the potential payouts and whether they were mixed or pure. A pure gamble involved choices with the same type of outcome. In other words, both choices were losses (e.g., 50/50 chance of losing $\$ 7$ or $\$ 11$ ) or both choices were gains (e.g., 50/50 chance of winning $\$ 15$ or $\$ 7$ ). A mixed gamble involved one loss outcome and one gain outcome (e.g., 50/50 chance of winning $\$ 10.50$ or losing $\$ 16.50$ ).

\section{Procedure}

This study used a double-blind, placebo controlled, within-subjects alcohol administration design with two counterbalanced sessions in which participants consumed an alcoholic beverage or a placebo beverage. Participants were asked to abstain from alcohol and drugs (recreational, prescribed, and over the counter) for 24 hours prior to participation. Participants were also asked to refrain from eating for at least 60 minutes prior to beginning the study. Study sessions began at 10:30 am. Participants provided informed consent and their sobriety was verified via a breathalyzer test. Women were given a urine pregnancy test (no participants tested positive). Participants then completed several computerized questionnaires listed above. Other questionnaires were administered but are not relevant to the current study. Ninety minutes prior to beverage administration, 
participants consumed a small meal ( $15 \%$ of recommended daily caloric intake based on sex, height, and weight) in order to equate participants on gastric content.

Alcohol dose was calculated based on gender, age, height, and weight to produce a peak $\mathrm{BrAC}$ of $0.10 \mathrm{~g} \%$ at 60 minutes post-beverage consumption. Doses were $0.85 \mathrm{~g} / \mathrm{kg}$ for men and $0.73 \mathrm{~g} / \mathrm{kg}$ for women. Beverages were administered at approximately 12:00 pm. The beverage in the alcohol session consisted 190-proof grain alcohol with orange juice in a 1:3 ratio. The beverage in the placebo session was a volumetrically equivalent beverage consisting of orange juice with $10 \%$ of their calculated alcohol dose floated on top. Beverages were divided equally into two glasses. Participants consumed each glass in one minute with a five-minute break between beverages.

$\mathrm{BrAC}$ was collected in five-minute intervals after participants consumed their second drink in both sessions. The decision-making task was administered at peak BrAC $(\sim 0.10 \mathrm{~g} \%)$ in the alcohol session. Timings in the placebo session were based on timings observed in a previous alcohol administration study, and the decision-making task was administered at a time equivalent to peak BrAC.

The placebo manipulation was verified by asking participants whether they believed they had received alcohol and how many drinks they received. In the alcohol session, participants remained in the laboratory until their BrAC was below $0.04 \mathrm{~g} \%$. In the placebo session, participants remained in the laboratory for 90 minutes after the conclusion of the study. Participants were debriefed at the end of the second session. All participants were compensated $\$ 12$ per hour and were transported home via a prepaid taxi or a friend.

\section{Analytic Strategy}

\section{Bayesian Classification of Risk Attitude.}


Risk attitude classification occurred in two ways:

(1) Global Classification: Bayesian model comparison was used to evaluate each person's choice data. The models considered were strictly risk seeking, strictly risk averse, strictly risk neutral, gain-loss sensitive (risk averse for gains, risk seeking for losses), high-stakes sensitive (risk seeking for small gains and all losses, risk averse for large gains), and mixedgambles sensitive (risk averse for gains and mixed gambles, risk seeking for losses). Each of these models was compared to a reference model to compute a Bayes factor. The model with the highest Bayes factor was selected as a participant's global risk attitude.

(2) Gamble-Specific Classification (Kellen et al., 2017): Choice data for each gamble type from each decision-making task was aggregated. Bayesian model comparison was used to evaluate each participant's choice data. Bayes factors were computed to assess the fit of the risk averse, risk neutral, and risk seeking models compared to a reference model for each type of gamble (pure gains, pure losses, mixed gains and losses, high stakes gains, high stakes losses, high stakes mixed gains and losses). The model with the highest Bayes factor represented a participant's risk attitude classification for a specific gamble type.

\section{Comparison of Risk Attitude in Alcohol and Placebo Sessions.}

The marginal homogeneity test, an extension of the McNemar test for categorical data, was used to determine differences in risk attitude classification proportions in the alcohol and placebo sessions. This test was conducted for Global Risk Attitude and Gamble-Specific Risk Attitude. Global Risk Attitude classifications were also recoded as "risk seeking" or "other/not risk seeking" to compare the proportions of risking seeking against all other classifications in the alcohol and placebo conditions. A McNemar test was used for this comparison. 


\section{Testing the Association of Risk Attitude and Alcohol-Related Behaviors.}

Bayesian inference was used to explore associations between risk attitude and conceptually related constructs: alcohol outcome expectancies, other risk-taking behavior attitudes, alcohol problems, alcohol demand, delay discounting, risk taking behaviors (alcohol impaired driving, risky sex), impulsivity (negative urgency, positive urgency, lack of perseverance, lack of planning, sensation seeking), reward sensitivity, and punishment sensitivity. A set of directional hypotheses between risk attitude classification and variables of interest was generated. For the purposes of these analyses, global risk attitude was used. Risk attitude was dummy coded as "risk seeking" and "other/not risk seeking." Those classified as risk seeking were compared to all other risk attitude classifications. These analyses were conducted separately for the alcohol and placebo sessions.

\section{Exploring the Effects of Risk Attitude Stability.}

Bayesian inference was used to better understand the association between risk attitude stability and alcohol-related behaviors. Risk attitude classifications in the alcohol and placebo sessions were compared, and participants were classified as (1) stable, (2) switch to a more risk seeking classification in the alcohol condition (relative to classification in the placebo condition), or (3) switch to a less risk seeking classification in the alcohol condition (relative to classification in placebo condition). Global risk attitude classifications were used or these analyses. These analyses tested whether switching status was associated with outcome variables previously identified (e.g., alcohol use, risk taking behaviors, personality traits). 


\section{Results}

\section{Global Risk Attitude Classification.}

Table 1 demonstrates risk attitude classifications in the placebo and alcohol conditions. Of the 50 participants who completed a placebo session, 20 participants (38.5\%) were unable to be classified. The remaining participants were classified as follows: risk seeking $(n=18,34.6 \%)$, risk averse $(n=7,13.5 \%)$, gain-loss sensitive $(n=3,5.8 \%)$, and mixed gambles sensitive $(n=2,3.8 \%)$. Of the 48 participants who completed an alcohol session, 17 participants $(32.7 \%)$ were unable to be classified. The remaining participants were classified as follows: risk seeking $(n=21,40.4 \%)$, risk neutral $(n=1$, $1.9 \%)$, risk averse $(n=4,7.7 \%)$, gain-loss sensitive $(n=3,5.8 \%$, and mixed gambles sensitive $(n=2,3.8 \%)$. No participants exhibited choice behavior consistent with the high stakes sensitive classification in either session.

\section{Comparison of Global Risk Attitude Classification in Alcohol and Placebo Conditions.}

The crosstabulation for the risk attitude classifications in the alcohol and placebo sessions can be found in Table 2. A total of 25 (54.3\%) participants switched classifications between the alcohol and placebo conditions, including those who were not classified in one of the sessions. Of those who switched, 13 (52\%) participants switched to a more risk seeking classification in the alcohol condition relative to their classification in the placebo condition (e.g., from not risk seeking in the placebo condition to risk seeking in alcohol condition). The remaining 12 (48\%) participants switched to a less seeking classification in the alcohol condition relative to their classification in the placebo condition (e.g., from risk seeking in the placebo condition to not risk seeking in the alcohol condition). A test of 
marginal homogeneity indicated that there were no significant differences in proportion of risk attitude classifications in the alcohol and placebo sessions $(p=0.94)$. The proportions of risk seeking in each condition (i.e., risk seeking vs. other/not risk seeking) were compared using a McNemar Test (see Table 3). The McNemar Test indicated that the distributions of risk seeking in the alcohol and placebo conditions were not significantly different $(p=0.58)$.

\section{Gamble Specific Risk Attitude Classification.}

Risk attitude classifications were determined for gains, losses, and mixed gambles separately (Kellen et al., 2017). Risk attitude classifications for gains, losses, and mixed gambles in the alcohol and placebo sessions are in Table 4. In the placebo condition, the classifications for gambles involving gains were as follows: not decisive/unclassified (n $=19,38 \%)$, risk averse $(\mathrm{n}=17,24 \%)$, risk seeking $(\mathrm{n}=10,20 \%)$, and risk neutral $(\mathrm{n}=4$, $8 \%)$. For gambles involving losses in the placebo condition, 23 participants were unable to be classified (46\%), 15 were risk seeking (30\%), 9 were risk neutral (18\%), and 3 were risk averse $(6 \%)$. For mixed gambles in the placebo condition, the following classifications were observed: risk seeking $(\mathrm{n}=23,46 \%)$, not decisive/unclassified $(\mathrm{n}=19,38 \%)$, risk neutral $(\mathrm{n}=4,8 \%)$, and risk averse $(\mathrm{n}=4,8 \%)$.

In the alcohol condition, classifications for gambles involving gains were as follows: not decisive/unclassified ( $\mathrm{n}=29,39.6 \%)$, risk seeking $(\mathrm{n}=15,31.3 \%)$, risk averse $(\mathrm{n}=11,22.9 \%)$, and risk neutral $(\mathrm{n}=3,6.3 \%)$. For gambles involving losses in the alcohol condition, 20 participants were unable to be classified (41.7\%), 16 were risk seeking (33.3\%), 8 were risk neutral (16.7\%), and 4 were risk averse (8.3\%). For mixed gambles 
in the alcohol condition, 19 were risk seeking (39.6\%), 19 were not decisive/unable to be classified (39.6\%), 7 were risk neutral (14.6\%), and 3 were risk averse (6.3\%).

\section{Comparison of Gamble Specific Risk Attitude Classification in Alcohol and Placebo}

\section{Conditions.}

For gambles involving gains, 20 participants (43.5\%) switched classifications between alcohol and placebo sessions, and of those 7 (35\%) became more risk seeking. Similar patterns were observed for gambles involving losses and mixed gambles. For losses, 19 participants (41.6\%) switched classifications, and 5 (26.3\%) of those became more risk seeking. For mixed gambles, 20 participants (43.5\%) switched classifications, and of those $5(25 \%)$ became more risk seeking. A crosstabulation of risk attitude classifications in the alcohol and placebo conditions for gains, losses, and mixed gambles can be found in Tables 5, 6, and 7 respectively. Test of marginal homogeneity indicated that there were no significant differences in proportions in the alcohol and placebo conditions for gains $(p=0.23)$, losses $(p=0.90)$, or mixed gambles $(p=0.54)$.

\section{Risk Attitude and Alcohol Involvement.}

Bayes factors for the relationship between risk attitude and indices of alcohol involvement are displayed in Table 8. These results suggest there are several associations between risk attitude and alcohol involvement, but only for risk attitude assessed under alcohol intoxication. In the alcohol condition, individuals who are risk seeking drink larger quantities, drink more frequently, and report more binge drinking episodes than those who are not risk seeking $(\mathrm{BF}=6.93$ for alcohol quantity; $\mathrm{BF}=10.36$ for alcohol frequency; $\mathrm{BF}$ $=20.14$ for binge drinking frequency). Risk seeking individuals are also more likely to experience alcohol consequences related to impaired control (e.g., "I often drank more than 
I originally had planned."; $\mathrm{BF}=3.17)$. The Bayes factor for the conjunction of all hypotheses involving alcohol consumption and consequences was 150.93, indicating strong evidence in support of the hypothesis that risk seeking individuals are more likely to drink more alcohol and experience more consequences when doing so. There is no evidence to suggest differences between risk seeking individuals and those who are not risk seeking in the placebo condition $(\mathrm{BF}=0.0001)$.

\section{Risk Attitude and Risk Taking Behaviors.}

Bayes factors for the association between risk attitude and risk taking behaviors are in Table 9. Specifically, alcohol impaired driving and past frequency of engaging in sexual behaviors with new and regular partners were considered. All the Bayes factors for these behaviors indicated that there is no evidence in this sample to support the hypothesis that those who are more risk seeking are more likely to engage in risk taking behavior in either condition (BF for conjunction of hypotheses in: alcohol condition= 0.10; placebo condition $=0.17$ ). Bayes factors ranged from 0.33 to 1.25 in the placebo condition and from 0.37 to 0.58 in the alcohol condition.

\section{Risk Attitude and Behavioral Economics.}

Bayes factors for the association between risk attitude and behavioral economic variables are in Table 10. The results indicate that demand for alcohol does not differ between those who are risk seeking and those who are not. There is slight evidence to suggest differences in discounting rates between those who are risk seeking and those who are not. This difference appears to be stronger in the placebo condition $(\mathrm{BF}=2.06)$ relative to the alcohol condition $(\mathrm{BF}=1.60)$. The Bayes factors for the conjunction of all hypotheses regarding behavioral economic indices does not support the hypothesis that 
individuals who are risk seeking would demonstrate higher demand for alcohol and higher rates of delay discounting $(\mathrm{BF}$ for alcohol condition $=0.23$; $\mathrm{BF}$ for placebo condition $=$ 0.29). Bayes factors ranged from 0.33 to 2.06 in the placebo condition and from 0.34 to 1.60 in the alcohol condition.

\section{Risk Attitude and Expectancies.}

Bayes factors for the association between risk attitude and expectancies and attitudes are in Table 11. The results indicate that there are no differences between alcohol outcome expectancies, perceived benefits of sexual behavior with a new partner, perceived risk of sexual behavior with a new partner, or perceived safe limit for alcohol-impaired driving. The same pattern of results occurred in the alcohol and placebo sessions. For the alcohol condition, Bayes factors ranged from 0.32 to 0.62 , and the Bayes factor for the conjunction of all hypotheses was 0.00002 . For the placebo condition, Bayes factors ranged from 0.33 to 1.67 , and the Bayes factor for the conjunction of all hypotheses was 0.00009 .

\section{Risk Attitude and Personality Traits.}

Bayes factors for the associations between risk attitude and personality traits are in Table 12. The results suggest that there is no evidence to support the hypothesis that those who are risk seeking are more likely to be impulsive or higher in reward sensitivity. There are no differences in the pattern of results between the alcohol and placebo conditions. For the alcohol condition, Bayes factors ranged from 0.33 to 0.47 , and the Bayes factor for the conjunction of all hypotheses was 0.001 . For the placebo condition, Bayes factors ranged from 0.33 to 0.52 , and the Bayes factor for the conjunction of all hypotheses was 0.002 . 


\section{Stability of Risk Attitude.}

Mean differences in variables of interest by patterns of switching were examined. Specifically, individuals who did not switch were compared with those who switched to become more risk seeking when intoxicated and those who switched to become less risk seeking when intoxicated. Bayes factors for these models indicated there is no evidence to suggest that there are differences between individuals who changed their risk attitude between the placebo and alcohol sessions and those who did not (see Table 13). Bayes factors ranged from 0.22 to 2.81 for alcohol involvement $(\mathrm{BF}$ for conjunction $=0.002)$, from 0.20 to 0.24 for behavior economics $(\mathrm{BF}$ for conjunction $=0.0008)$, from 0.20 to 0.50 for impulsive personality traits $(\mathrm{BF}$ for conjunction $=0.0001)$, from 0.26 to 1.92 for risk taking behaviors $(\mathrm{BF}$ for conjunction $=0.25)$, and from 0.20 to 0.67 for outcome expectancies and attitudes $(\mathrm{BF}$ for conjunction $=0.000002)$. 


\section{Discussion}

This study aimed to examine the role of decision making under risk in alcoholrelated risk taking. Results from this study indicate that while acute alcohol intoxication does not significantly affect risk attitude within person, intoxicated risk attitude is associated with indices of alcohol consumption. Specifically, individuals classified as risk seeking when intoxicated were more likely to drink more heavily and more frequently and experience more alcohol-related negative consequences in the past than their non-risk seeking counterparts. This pattern was not present for risk attitude assessed in the placebo condition. Furthermore, the results of this study suggest that risk attitude is not related to impulsive personality traits, risk taking behaviors, or behavioral economic indices of alcohol involvement, regardless of whether it is assessed under alcohol intoxication or in the placebo condition.

Risk attitude assessed in the placebo condition demonstrated no association with indices of alcohol involvement, nor was there a main effect of alcohol intoxication on risk attitude. These results suggests that intoxicated risk attitude may provide distinct information about risk for alcohol misuse, as those who are risk seeking while intoxicated are more likely to drink heavily. Furthermore, those who are risk seeking while intoxicated are at a greater risk for experiencing consequences due to impaired control of drinking (i.e.,

drinking more than originally planned). Alcohol consumption itself is not necessarily a risk-taking behavior. Rather, higher rates of alcohol consumption may place one at risk for experiencing negative consequences, developing health problems, or engaging in other risk-taking behaviors (Fillmore, 2003). The results of this study suggest that altering one's 
approach to risk while intoxicated may serve as an early intervention target for the purpose of reducing alcohol consumption and downstream negative consequences.

The results of the current study are consistent with previous research suggesting that alcohol intoxication does not acutely affect performance on behavioral tasks of decision making or related constructs (Adams et al., 2016; Bidwell, et al., 2013; DavisStober et al., 2019; Erskine-Shaw et al., 2017; Johnson et al., 2016; Peacock et al., 2015; Weafer \& Fillmore, 2016; Wray et al., 2015). Previous studies have suggested that alcohol may differentially affect aspects of decision making. For instance, alcohol intoxication is associated with risky decision making on a probability discounting task but not in a delay discounting task (Bidwell et al., 2013). Thus, alcohol intoxication may not affect the process by which individuals evaluate risk on this task. In addition, the results of the current study do not identify any differences between individuals who exhibited different risk attitude under intoxication versus under placebo relative to those with stable risk attitude, providing further evidence that acute intoxication does not affect risk attitude in a meaningful way. Despite the null effects of acute alcohol intoxication, intoxicated risk attitude only was associated with alcohol use behavior, highlighting the importance of understanding risk attitude while intoxicated, regardless of one's risk attitude when sober.

The null associations between risk attitude and expectancies and attitudes, risk taking behaviors, and indices of behavior economics call into question the possible utility of using monetary gamble tasks to predict risk taking behaviors in other contexts. Monetary gambles tasks have a well-established role for financial and economic risk taking (e.g., investing in stocks). Gambling is another financial risk-taking behavior that was not assessed in this study. As the decision-making task used in this study specifically involves 
decisions involving financial risk, it is possible that this task may be more related to financial risk taking than other varieties of risk taking. Studies on gambling have suggested that risk perception and risk attitude are associated with gambling behavior and have argued for the importance of domain-specific risk attitude assessments (Deck et al., 2014; Fujimoto et al., 2017; Spurrier \& Blaszczynski, 2014). Of note, delay discounting measures and the decision-making task used in this study both involved monetary choices. The delay discounting measure was self-report, and previous studies have suggested that self-report and behavioral measures perform differently and are often weakly correlated (Dang et al., 2020). Thus, while risk attitude does not appear to be associated with paper-and-pencil measures of delay discounting, it is possible it would be associated with behavioral measures of delay discounting.

Recent studies have indicated that the context of decision making is important for understanding decision making processes of risk-taking behavior. A self-report measure of domain specific risk taking, Domain-Specific Risk Taking, has demonstrated the importance of assessing risk attitude in various contexts (Blais \& Weber, 2006), suggesting that within-person variability in risk taking across different domains is much larger than between-person differences in risk taking. More recently, decision making tasks have been developed for specific behaviors (e.g., alcohol impaired driving, risky sexual behavior). One such task for alcohol impaired driving asks participants to make hypothetical decisions about driving based on the amount of alcohol they have consumed and the cost of an alternative ride home (McCarthy et al., 2020). Decision making patterns on this task were found to be associated with past alcohol impaired driving behavior. Similarly, a task on sexual decision making asks participants to select their preferred hypothetical sexual 
partner when considering the potential partner's level of attractiveness and the risk of contracting a sexually transmitted infection from that person (Hatz et al., 2020). Decision making strategies on this task are associated with real world sexual risk-taking behavior. The decision-making task used in this study assessed risk using monetary gambles, while many other relevant variables (e.g., expectancies and attitudes) assessed were behavior specific. Alcohol demand specifically assesses motivation for alcohol consumption based on willingness to spend money on alcohol (Murphy \& MacKillop, 2006). A decisionmaking task more focused on the purchase of alcohol or risks associated with buying drinks may have resulted in more apparent associations. Alternatively, a version of this task that eliminates the monetary component may be beneficial for better understanding alcohol related risk taking.

The results of this study are also consistent with existing literature that laboratory measures of risk attitude are not associated with real world risk taking (Charness et al., 2020). Furthermore, several studies have suggested that simple, self-report measures of risk attitude outperform behavioral tasks in predicting real-world behavior (Arslan et al., 2020; Charness et al., 2020). Arslan and colleagues (2020) conducted a large study in which participants were asked to explain the reasoning behind their responses to a single item measure of risk attitude: "How do you see yourself: Are you generally a person who is fully prepared to take risks or do you try to avoid taking risks?" rated on a 0 to 10 scale ("unwilling to take risks" to "fully prepared to take risks"). Participants reportedly focused on past behaviors and experiences that were believed to be representative of their general risk attitude. Notably, most participants reported focusing on risks that they took rather than risks they avoided when answering this question (Arslan et al., 2020). In the current 
study, participants experience with money management or financial risk was not assessed. Lack of familiarity with gambling or finances may have contributed to the null finding with risk taking behaviors, as participants task behavior may change as they accumulate more experience of financial risks to inform their choices.

The current study recruited healthy, social drinkers without a history of alcohol use disorder. It is possible that an association between measures of risk attitude and reward sensitivity and impulsivity would be observed in heavier drinking sample. Deficiencies in reward processing or reward sensitivity ultimately develop among those with substance use disorders (Berridge \& Robinson, 2003; Carlson et al., 2011). The nature of the study may have artificially excluded those with more problematic levels of reward sensitivity and impulsivity, limiting its association with other potentially relevant variables. Alternatively, risk attitude may function differently than personality traits. The null funding between risk attitude and alcohol outcome expectancies supports this possible explanation. The Acquired Preparedness Model suggests that impulsive personality traits bias one's learning, such that they are more likely to endorse positive alcohol outcome expectancies and experience more problematic outcomes due to substance use (Smith \& Anderson, 2001). The lack of association between risk attitude and expectancies suggests that risk attitude may function differently than stable traits, and instead may be more specific to contexts in which risks occur.

Individuals with a substance use disorder have also likely progressed further in the development of substance related dysfunctional decision making. A stronger association between risk attitude and alcohol problems or alcohol-related risk taking (e.g., alcohol impaired driving) may be expected in a sample that included individuals with more severe 
and problematic patterns of alcohol use. Of note, severity of substance use has been associated with risky decision making on similar tasks (e.g., BART; Fishbein et al., 2007; Hanson et al., 2014; Wittwer et al., 2016), and is consistent with the finding that individuals with substance use disorders prefer risky over safe options (Brand et al., 2008; Brevers et al., 2014; Fishbein et al., 2007; Hanson et al., 2014; Wittwer et al., 2016). Previous studies suggest that individuals with substance use disorders are likely to exhibit risk taking when stakes are high, suggesting that reward sensitivity is an important factor in the development of risk attitude (Brand et al., 2008; Brevers et al., 2014). Of note, there were no participants in this study who exhibited behavior on the decision-making task that was consistent with the high stakes sensitive classification, indicating that participants did not make different choices when presented with high stakes or low stakes.

The results of the current study should be considered in the context of several limitations. The sample used for this study was homogenous, limiting its generalizability. Specifically, the sample was comprised of mostly white, social drinkers in a Midwestern college town. These results may have been in samples with different characteristics. In addition, this study involved alcohol consumption in a laboratory and not the participant's natural drinking setting. Decision making processes and risk attitude may be different outside the lab. Risk attitude assessed in natural drinking environments may demonstrate stronger relationships with risk taking behaviors that occur while drinking (e.g., alcohol impaired driving). The sample size for this study was relatively small which limited the possibility of detecting effects of alcohol intoxication. Some of these concerns are mitigated by using Bayesian analyses, but tests of marginal homogeneity may be affected by a small sample size. 
The current study examined the effect of acute alcohol intoxication on a task measuring decision making under risk. The results of the study suggest that intoxicated risk attitude is associated with indices of alcohol consumption and to a lesser extent, alcohol consequences. Importantly, alcohol intoxication did not significantly impact risk attitude classification. Risk attitude was not associated with impulsive personality traits, alcohol expectancies, or risk-taking behaviors. Altering intoxicated risk attitude may serve as an early intervention target for reducing rates of alcohol consumption and subsequent negative consequences or risk-taking behaviors. While risk attitude may have utility for identifying those who are at risk for alcohol problems, tasks designed to assess behavior specific decision processes may be useful for understanding risky patterns of decision making. 
Figure 1. Example gamble from decision making task.

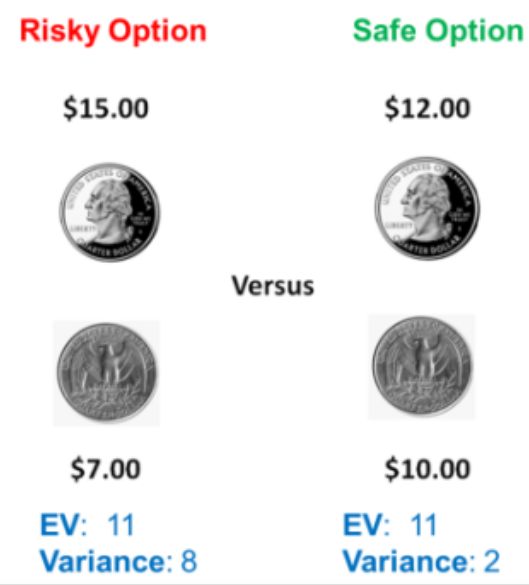




\section{Table 1}

Global Risk Attitude Classifications in Alcohol and Placebo Conditions

\begin{tabular}{lll}
\hline & Alcohol & Placebo \\
\hline RS & $21(43.8 \%)$ & $18(36 \%)$ \\
RN & $1(2.1 \%)$ & $0(0 \%)$ \\
RA & $4(8.3 \%)$ & $7(14 \%)$ \\
GLS & $3(6.3 \%)$ & $3(6 \%)$ \\
HSS & $0(0 \%)$ & $0(0 \%)$ \\
MGS & $2(4.2 \%)$ & $2(4 \%)$ \\
NC & $17(35.4 \%)$ & $20(40 \%)$ \\
\hline
\end{tabular}


Table 2

Crosstabulation for Global Risk Attitude in Alcohol and Placebo Conditions

\begin{tabular}{cllllllll}
\cline { 3 - 8 } & & \multicolumn{7}{c}{ Alcohol } \\
\cline { 2 - 8 } Placebo & RS & RN & RA & GLS & HSS & MGS & NC \\
\hline \multirow{5}{*}{} & RS & 12 & - & 1 & - & - & - & 3 \\
& RN & - & - & - & - & - & - & - \\
& RA & 1 & 1 & 1 & - & - & - & 2 \\
& GLS & 1 & - & - & - & - & 1 & 1 \\
& HSS & - & - & - & - & - & - & - \\
& MGS & - & - & - & 1 & - & - & 1 \\
& NC & 7 & - & 2 & 2 & - & 1 & 8 \\
\hline
\end{tabular}


Table 3

Risk Seeking vs. Other Classifications

\begin{tabular}{llll}
\cline { 3 - 3 } & & \multicolumn{2}{c}{ Alcohol } \\
\cline { 3 - 4 } & & Not Risk Seeking & Risk Seeking \\
\hline \multirow{2}{*}{ Placebo } & Not Risk Seeking & 21 & 8 \\
& Risk Seeking & 5 & 12 \\
\hline
\end{tabular}




\section{Table 4}

Gamble Specific Risk Attitude Classifications in Alcohol and Placebo Conditions

\begin{tabular}{lllllll}
\hline & \multicolumn{2}{c}{ Gains } & \multicolumn{2}{c}{ Losses } & \multicolumn{2}{c}{ Mixed } \\
\hline & Alcohol & Placebo & Alcohol & Placebo & Alcohol & Placebo \\
\hline Risk & 15 & 10 & 16 & 15 & 19 & 23 \\
Seeking & $(31.3 \%)$ & $(20 \%)$ & $(33.3 \%)$ & $(30 \%)$ & $(39.6 \%)$ & $(46 \%)$ \\
Risk & 3 & 4 & 8 & 9 & 7 & 4 \\
Neutral & $(6.3 \%)$ & $(8 \%)$ & $(16.7 \%)$ & $(18 \%)$ & $(14.6 \%)$ & $(8 \%)$ \\
Risk & 11 & 17 & 4 & 3 & 3 & 4 \\
Averse & $(22.9 \%)$ & $(34 \%)$ & $(8.3 \%)$ & $(6 \%)$ & $(6.3 \%)$ & $(8 \%)$ \\
Not & 29 & 19 & 20 & 23 & 19 & 19 \\
Decisive & $(39.6 \%)$ & $(38 \%)$ & $(41.7 \%)$ & $(46 \%)$ & $(39.6 \%)$ & $(38 \%)$ \\
\hline
\end{tabular}




\section{Table 5}

Crosstabulation for Gamble Specific Risk Attitude (Gains) in Alcohol and Placebo Condition

\begin{tabular}{llllll}
\cline { 3 - 5 } & & \multicolumn{3}{c}{ Alcohol } \\
\cline { 3 - 5 } & $\begin{array}{l}\text { Risk } \\
\text { Seeking }\end{array}$ & $\begin{array}{l}\text { Risk } \\
\text { Neutral }\end{array}$ & $\begin{array}{l}\text { Risk } \\
\text { Averse }\end{array}$ & $\begin{array}{l}\text { Not } \\
\text { Decisive }\end{array}$ \\
\hline \multirow{5}{*}{ Placebo } & $\begin{array}{l}\text { Risk } \\
\text { Seeking }\end{array}$ & 8 & - & - & 2 \\
Risk & - & 1 & - & 3 \\
Neutral & $\begin{array}{l}\text { Risk } \\
\text { Averse }\end{array}$ & 3 & 1 & 7 & 4 \\
Not & 3 & - & 4 & 10 \\
\hline
\end{tabular}


Table 6

Crosstabulation for Gamble Specific Risk Attitude (Losses) in Alcohol and Placebo Condition

\begin{tabular}{llllll}
\cline { 3 - 5 } & & \multicolumn{3}{c}{ Alcohol } \\
\cline { 3 - 5 } & $\begin{array}{l}\text { Risk } \\
\text { Seeking }\end{array}$ & $\begin{array}{l}\text { Risk } \\
\text { Neutral }\end{array}$ & $\begin{array}{l}\text { Risk } \\
\text { Averse }\end{array}$ & $\begin{array}{l}\text { Not } \\
\text { Decisive }\end{array}$ \\
\hline \multirow{5}{*}{ Placebo } & $\begin{array}{l}\text { Risk } \\
\text { Seeking }\end{array}$ & 10 & - & - & 5 \\
Risk & - & 5 & 1 & 2 \\
Neutral & $\begin{array}{l}\text { Risk } \\
\text { Averse } \\
\text { Not }\end{array}$ & - & - & 1 & 2 \\
Decisive & 5 & 2 & 2 & 11 \\
\hline
\end{tabular}




\section{Table 7}

Crosstabulation for Gamble Specific Risk Attitude (Mixed) in Alcohol and Placebo Condition

\begin{tabular}{llllll}
\cline { 3 - 5 } & & \multicolumn{3}{c}{ Alcohol } \\
\cline { 3 - 5 } & $\begin{array}{l}\text { Risk } \\
\text { Seeking }\end{array}$ & $\begin{array}{l}\text { Risk } \\
\text { Neutral }\end{array}$ & $\begin{array}{l}\text { Risk } \\
\text { Averse }\end{array}$ & $\begin{array}{l}\text { Not } \\
\text { Decisive }\end{array}$ \\
\hline \multirow{5}{*}{ Placebo } & 14 & 1 & - & 7 \\
& $\begin{array}{l}\text { Risk } \\
\text { Seeking }\end{array}$ & 1 & 1 & - & 1 \\
Risk & $\begin{array}{l}\text { Neutral } \\
\text { Risk } \\
\text { Averse }\end{array}$ & - & 1 & 1 & 1 \\
Not & 3 & 3 & 2 & 10 \\
\hline
\end{tabular}




\section{Table 8}

Bayes Factor Results from Comparisons of Risk Seeking to Other Classifications for Alcohol Involvement

\begin{tabular}{|c|c|c|c|c|c|c|c|}
\hline \multirow[b]{2}{*}{ Variable } & \multirow[b]{2}{*}{ Hypothesis } & \multicolumn{3}{|c|}{ Alcohol } & \multicolumn{3}{|c|}{ Placebo } \\
\hline & & $\begin{array}{l}\text { Risk } \\
\text { Seeking }\end{array}$ & $\begin{array}{l}\text { Not } \\
\text { Risk } \\
\text { Seeking }\end{array}$ & $\begin{array}{l}\text { Bayes } \\
\text { Factor }\end{array}$ & $\begin{array}{l}\text { Risk } \\
\text { Seeking }\end{array}$ & $\begin{array}{l}\text { Not } \\
\text { Risk } \\
\text { Seeking }\end{array}$ & $\begin{array}{l}\text { Bayes } \\
\text { Factor }\end{array}$ \\
\hline YAACQ Total & RS $>$ not RS & 17.84 & 13.06 & 0.94 & 16.6 & 14.86 & 0.37 \\
\hline $\begin{array}{l}\text { Social/Interpersonal } \\
\text { Alcohol Problems }\end{array}$ & $\mathrm{RS}>$ not RS & 2.68 & 2.29 & 0.38 & 2.47 & 2.52 & 0.33 \\
\hline $\begin{array}{l}\text { Impaired Control } \\
\text { Alcohol Problems }\end{array}$ & $\mathrm{RS}>$ not RS & 2.32 & 1.18 & 3.17 & 2.13 & 1.52 & 0.58 \\
\hline $\begin{array}{l}\text { Self-Perception } \\
\text { Alcohol Problems }\end{array}$ & $\mathrm{RS}>$ not RS & 0.68 & 0.82 & 0.34 & 0.53 & 0.90 & 0.49 \\
\hline $\begin{array}{l}\text { Self-Care Alcohol } \\
\text { Problems }\end{array}$ & $\mathrm{RS}>$ not RS & 2.21 & 2.12 & 0.32 & 2.4 & 2.0 & 0.38 \\
\hline $\begin{array}{l}\text { Risky Behaviors } \\
\text { Alcohol Problems }\end{array}$ & $\mathrm{RS}>$ not RS & 2.89 & 2.24 & 0.44 & 2.33 & 2.76 & 0.37 \\
\hline $\begin{array}{l}\text { Academic/ } \\
\text { Occupational Alcohol } \\
\text { Problems }\end{array}$ & $\mathrm{RS}>$ not RS & 1.53 & 0.59 & 1.91 & 1.2 & 1.0 & 0.35 \\
\hline $\begin{array}{l}\text { Physiological } \\
\text { Dependence Alcohol } \\
\text { Problems }\end{array}$ & $\mathrm{RS}>$ not $\mathrm{RS}$ & 0.53 & 0.35 & 0.41 & 0.53 & 0.38 & 0.39 \\
\hline $\begin{array}{l}\text { Blackout Drinking } \\
\text { Alcohol Problems }\end{array}$ & $\mathrm{RS}>$ not $\mathrm{RS}$ & 5 & 3.47 & 2.37 & 5 & 3.76 & 1.11 \\
\hline Drinking Quantity & $\mathrm{RS}<$ not RS & 6.63 & 7.88 & 7.19 & 6.93 & 7.43 & 0.49 \\
\hline Drinking Frequency & $\mathrm{RS}<$ not RS & 3.48 & 4.35 & 10.36 & 3.6 & 4.10 & 0.84 \\
\hline $\begin{array}{l}\text { Binge Drinking } \\
\text { Frequency }\end{array}$ & $\mathrm{RS}<$ not $\mathrm{RS}$ & 4.58 & 6.06 & 20.14 & 5.2 & 5.33 & 0.33 \\
\hline Conjunction & & & & 150.93 & & & $1.00 \mathrm{e}-4$ \\
\hline
\end{tabular}

Note. YAACQ $=$ Young Adult Alcohol Consequences Questionnaire 


\section{Table 9}

Bayes Factor Results from Comparisons of Risk Seeking to Other Classifications for Risk Taking Behaviors

\begin{tabular}{|c|c|c|c|c|c|c|c|}
\hline & & & Alcohol & & & Placebo & \\
\hline Variable & Hypothesis & $\begin{array}{l}\text { Risk } \\
\text { Seeking }\end{array}$ & $\begin{array}{l}\text { Not } \\
\text { Risk } \\
\text { Seeking }\end{array}$ & $\begin{array}{l}\text { Bayes } \\
\text { Factor }\end{array}$ & $\begin{array}{l}\text { Risk } \\
\text { Seeking }\end{array}$ & $\begin{array}{l}\text { Not } \\
\text { Risk } \\
\text { Seeking }\end{array}$ & $\begin{array}{l}\text { Bayes } \\
\text { Factor }\end{array}$ \\
\hline AID & $\mathrm{RS}>$ not $\mathrm{RS}$ & 4.32 & 14.56 & 0.45 & 4.27 & 12.67 & 0.40 \\
\hline $\begin{array}{l}\text { Past } \\
\text { Frequency of } \\
\text { Sex with } \\
\text { Regular } \\
\text { Partner }\end{array}$ & $\mathrm{RS}>$ not RS & 3.59 & 3.29 & 0.37 & 3.51 & 3.41 & 0.33 \\
\hline $\begin{array}{l}\text { Past } \\
\text { Frequency of } \\
\text { Sex with New } \\
\text { Partner }\end{array}$ & $\mathrm{RS}>$ not $\mathrm{RS}$ & 1.45 & 1.16 & 0.58 & 1.57 & 1.12 & 1.25 \\
\hline Conjunction & & & & 0.10 & & & 0.17 \\
\hline
\end{tabular}

Note. AID = Alcohol-impaired Driving 


\section{Table 10}

Bayes Factor Results from Comparisons of Risk Seeking to Other Classifications for Behavioral Economics

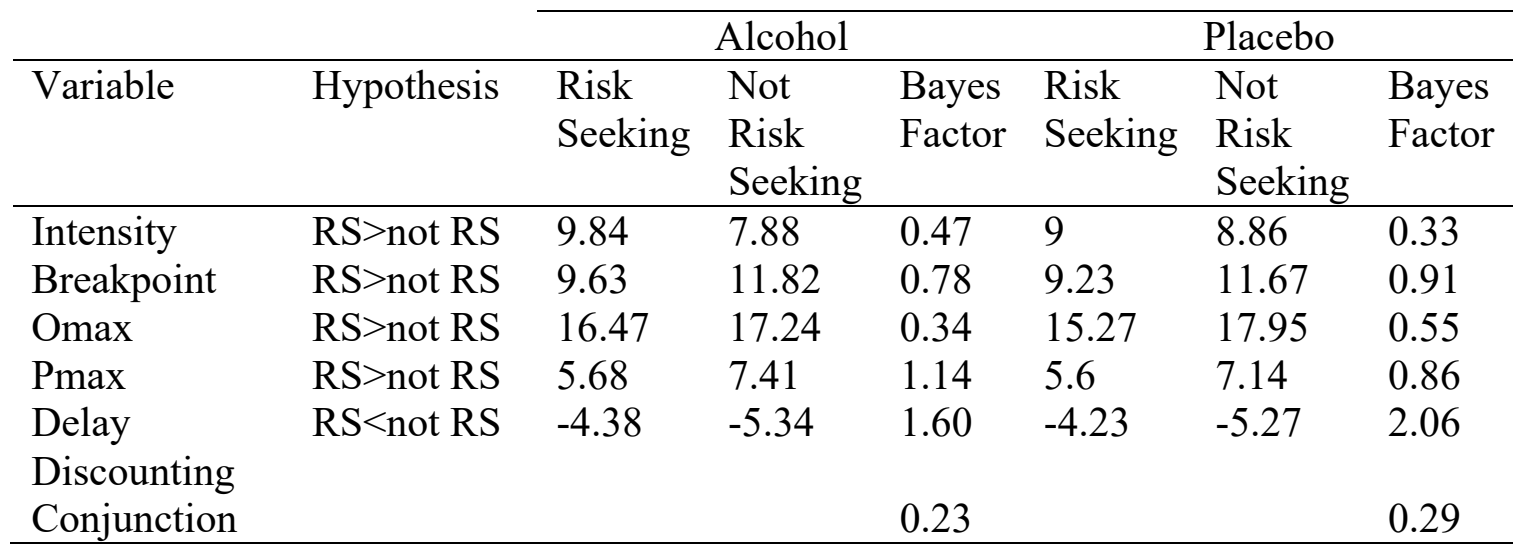




\section{Table 11}

Bayes Factor Results from Comparisons of Risk Seeking to Other Classifications for Expectancies

\begin{tabular}{|c|c|c|c|c|c|c|c|}
\hline & & & Alcohol & & & Placebo & \\
\hline Variable & Hypothesis & $\begin{array}{l}\text { Risk } \\
\text { Seeking }\end{array}$ & $\begin{array}{l}\text { Not Risk } \\
\text { Seeking }\end{array}$ & $\begin{array}{l}\text { Bayes } \\
\text { Factor }\end{array}$ & $\begin{array}{l}\text { Risk } \\
\text { Seeking }\end{array}$ & $\begin{array}{l}\text { Not Risk } \\
\text { Seeking }\end{array}$ & $\begin{array}{l}\text { Bayes } \\
\text { Factor }\end{array}$ \\
\hline Perceived Safe Limit & $\begin{array}{l}\text { RS }>\text { not } \\
\text { RS }\end{array}$ & 3.21 & 2.94 & 0.36 & 3.07 & 3.10 & 0.33 \\
\hline $\begin{array}{l}\text { Sociability Alcohol } \\
\text { Expectancies }\end{array}$ & $\begin{array}{l}\text { RS }>\text { not } \\
\text { RS }\end{array}$ & 3.44 & 3.27 & 0.54 & 3.50 & 3.26 & 0.89 \\
\hline $\begin{array}{l}\text { Tension Reduction } \\
\text { Alcohol Expectancies }\end{array}$ & $\begin{array}{l}\mathrm{RS}>\text { not } \\
\mathrm{RS}\end{array}$ & 2.70 & 2.63 & 0.40 & 2.89 & 2.51 & 1.67 \\
\hline $\begin{array}{l}\text { Liquid Courage } \\
\text { Alcohol Expectancies }\end{array}$ & $\begin{array}{l}\mathrm{RS}>\text { not } \\
\mathrm{RS}\end{array}$ & 2.75 & 2.94 & 0.41 & 2.84 & 2.84 & 0.33 \\
\hline $\begin{array}{l}\text { Sexuality Alcohol } \\
\text { Expectancies }\end{array}$ & $\begin{array}{l}\mathrm{RS}>\text { not } \\
\mathrm{RS}\end{array}$ & 2.45 & 2.53 & 0.36 & 2.63 & 2.38 & 1.04 \\
\hline $\begin{array}{l}\text { Cognitive \& } \\
\text { Behavioral } \\
\text { Impairment Alcohol } \\
\text { Expectancies }\end{array}$ & $\begin{array}{l}\mathrm{RS}>\text { not } \\
\mathrm{RS}\end{array}$ & 2.66 & 2.90 & 0.62 & 2.78 & 2.77 & 0.33 \\
\hline $\begin{array}{l}\text { Risk and Aggression } \\
\text { Alcohol Expectancies }\end{array}$ & $\begin{array}{l}\text { RS }>\text { not } \\
\text { RS }\end{array}$ & 2.67 & 2.71 & 0.32 & 2.65 & 2.71 & 0.33 \\
\hline $\begin{array}{l}\text { Self-Perception } \\
\text { Alcohol Expectancies }\end{array}$ & $\begin{array}{l}\mathrm{RS}>\text { not } \\
\mathrm{RS}\end{array}$ & 1.62 & 1.72 & 0.36 & 1.60 & 1.71 & 0.37 \\
\hline $\begin{array}{l}\text { Risk of Sex with } \\
\text { Regular Partner }\end{array}$ & $\begin{array}{l}\mathrm{RS}>\text { not } \\
\mathrm{RS}\end{array}$ & 2.79 & 2.43 & 0.44 & 2.45 & 2.74 & 0.40 \\
\hline $\begin{array}{l}\text { Risk of Sex with } \\
\text { New Partner }\end{array}$ & $\begin{array}{l}\text { RS }>\text { not } \\
\text { RS }\end{array}$ & 5.44 & 5.15 & 0.35 & 5.43 & 5.21 & 0.34 \\
\hline $\begin{array}{l}\text { Benefits of Sex with } \\
\text { Regular Partner }\end{array}$ & $\begin{array}{l}\mathrm{RS}>\text { not } \\
\mathrm{RS}\end{array}$ & 4.68 & 4.69 & 0.32 & 2.08 & 4.41 & 0.83 \\
\hline $\begin{array}{l}\text { Benefits of Sex with } \\
\text { New Partner }\end{array}$ & $\begin{array}{l}\text { RS }>\text { not } \\
\text { RS }\end{array}$ & 1.84 & 2.26 & 0.45 & 2.16 & 1.95 & 0.35 \\
\hline Conjunction & & & & $1.82 \mathrm{e}-5$ & & & $9.2 e-5$ \\
\hline
\end{tabular}




\section{Table 12}

Bayes Factor Results from Comparisons of Risk Seeking to Other Classifications for Personality Traits

\begin{tabular}{|c|c|c|c|c|c|c|c|}
\hline \multirow{3}{*}{ Variable } & \multirow{3}{*}{ Hypothesis } & \multicolumn{3}{|c|}{ Alcohol } & \multicolumn{3}{|c|}{ Placebo } \\
\hline & & Risk & Not & Bayes & Risk & Not & Bayes \\
\hline & & Seeking & Risk & Factor & Seeking & Risk & Factor \\
\hline Negative & $\mathrm{RS}>$ not & 2.04 & 2.12 & 037 & 207 & 209 & 033 \\
\hline Urgency & $\mathrm{RS}$ & & & & & & \\
\hline Lack of & $\mathrm{RS}>$ not & 1.93 & 2.04 & 0.41 & 1.94 & 2.02 & 0.36 \\
\hline Premeditation & $\mathrm{RS}$ & & & & & & \\
\hline Lack of & $\mathrm{RS}>$ not & 1.96 & 2.05 & 0.35 & 1.89 & 2.09 & 0.50 \\
\hline Perseverance & $\mathrm{RS}$ & & & & & & \\
\hline Sensation & $\mathrm{RS}>$ not & 3.04 & 3.23 & 0.47 & 3.21 & 3.08 & 0.39 \\
\hline Seeking & $\mathrm{RS}$ & & & & & & \\
\hline Positive & $\mathrm{RS}>$ not & 1.75 & 1.68 & 0.35 & 1.61 & 1.80 & 0.52 \\
\hline Urgency & $\mathrm{RS}$ & & & & & & \\
\hline Sensitivity to & $\mathrm{RS}>$ not & 0.55 & 0.60 & 0.45 & 0.59 & 0.55 & 0.40 \\
\hline Reward & $\mathrm{RS}$ & & & & & & \\
\hline Sensitivity to & $\mathrm{RS}>$ not & 0.36 & 0.34 & 0.33 & 0.35 & 0.34 & 0.33 \\
\hline Punishment & $\mathrm{RS}$ & & & & & & \\
\hline Conjunction & & & & 0.001 & & & 0.002 \\
\hline
\end{tabular}




\section{Table 13}

\section{Bayes Factor Results from Risk Attitude Stability}

\begin{tabular}{|c|c|c|c|c|}
\hline Variable & No Switch & $\begin{array}{l}\text { Switch to less } \\
\text { Risk Seeking in } \\
\text { Alcohol } \\
\text { Condition }\end{array}$ & $\begin{array}{l}\text { Switch to more } \\
\text { Risk Seeking in } \\
\text { Alcohol } \\
\text { Condition }\end{array}$ & Bayes Factor \\
\hline YAACQ Total & 18.65 & 11.3 & 14.56 & 1.04 \\
\hline $\begin{array}{l}\text { Social/Interpersonal } \\
\text { Alcohol Problems }\end{array}$ & 2.65 & 2.2 & 2.56 & 0.22 \\
\hline $\begin{array}{l}\text { Impaired Control } \\
\text { Alcohol Problems }\end{array}$ & 2.35 & 0.8 & 1.78 & 2.81 \\
\hline $\begin{array}{l}\text { Self-Perception } \\
\text { Alcohol Problems }\end{array}$ & 0.94 & 0.6 & 0.56 & 0.28 \\
\hline $\begin{array}{l}\text { Self-Care Alcohol } \\
\text { Problems }\end{array}$ & 2.71 & 2.1 & 1.22 & 0.67 \\
\hline $\begin{array}{l}\text { Risky Behaviors } \\
\text { Alcohol Problems }\end{array}$ & 3.00 & 1.7 & 2.78 & 0.41 \\
\hline $\begin{array}{l}\text { Academic/ } \\
\text { Occupational Alcohol } \\
\text { Problems }\end{array}$ & 1.29 & 0.5 & 1.33 & 0.45 \\
\hline $\begin{array}{l}\text { Physiological } \\
\text { Dependence Alcohol } \\
\text { Problems }\end{array}$ & 0.65 & 0.3 & 0.22 & 0.60 \\
\hline $\begin{array}{l}\text { Blackout Drinking } \\
\text { Alcohol Problems }\end{array}$ & 5.06 & 3.1 & 4.11 & 1.52 \\
\hline Drinking Quantity & 3.82 & 4.2 & 3.67 & 0.57 \\
\hline Drinking Frequency & 6.94 & 7.9 & 7.00 & 0.33 \\
\hline $\begin{array}{l}\text { Binge Drinking } \\
\text { Frequency }\end{array}$ & 5.12 & 6.0 & 4.78 & 0.64 \\
\hline Conjunction & & & & 0.002 \\
\hline Variable & No Switch & $\begin{array}{l}\text { Switch to less } \\
\text { Risk Seeking in } \\
\text { Alcohol } \\
\text { Condition }\end{array}$ & $\begin{array}{l}\text { Switch to more } \\
\text { Risk Seeking in } \\
\text { Alcohol } \\
\text { Condition }\end{array}$ & Bayes Factor \\
\hline AID & 3.56 & 24.1 & 3.56 & 0.50 \\
\hline $\begin{array}{l}\text { Past Frequency of Sex } \\
\text { with Regular Partner }\end{array}$ & 3.65 & 3.44 & 3.10 & 0.26 \\
\hline $\begin{array}{l}\text { Past Frequency of Sex } \\
\text { with New Partner }\end{array}$ & 1.61 & 1.03 & 1.30 & 1.92 \\
\hline Conjunction & & & & 0.25 \\
\hline Variable & No Switch & $\begin{array}{l}\text { Switch to less } \\
\text { Risk Seeking in } \\
\text { Alcohol } \\
\text { Condition }\end{array}$ & $\begin{array}{l}\text { Switch to more } \\
\text { Risk Seeking in } \\
\text { Alcohol } \\
\text { Condition } \\
\end{array}$ & Bayes Factor \\
\hline Intensity & 9.18 & 8.3 & 9.11 & 0.21 \\
\hline Breakpoint & 10.71 & 10.9 & 10.33 & 0.20 \\
\hline Omax & 16.29 & 17.9 & 16.67 & 0.22 \\
\hline Pmax & 6.35 & 7.2 & 6.00 & 0.26 \\
\hline $\begin{array}{l}\text { Delay Discounting } \\
\text { Conjunction }\end{array}$ & -4.54 & -5.30 & -4.87 & $\begin{array}{l}0.34 \\
0.0008\end{array}$ \\
\hline Variable & No Switch & $\begin{array}{l}\text { Switch to less } \\
\text { Risk Seeking in } \\
\text { Alcohol } \\
\text { Condition } \\
\end{array}$ & $\begin{array}{l}\text { Switch to more } \\
\text { Risk Seeking in } \\
\text { Alcohol } \\
\text { Condition }\end{array}$ & Bayes Factor \\
\hline
\end{tabular}




\begin{tabular}{|c|c|c|c|c|}
\hline Perceived Safe Limit & 3.18 & 3.30 & 2.67 & 0.26 \\
\hline $\begin{array}{l}\text { Sociability Alcohol } \\
\text { Expectancies }\end{array}$ & 3.35 & 3.35 & 3.39 & 0.20 \\
\hline $\begin{array}{l}\text { Tension Reduction } \\
\text { Alcohol Expectancies }\end{array}$ & 2.71 & 2.83 & 2.41 & 0.49 \\
\hline $\begin{array}{l}\text { Liquid Courage } \\
\text { Alcohol Expectancies }\end{array}$ & 2.84 & 2.96 & 2.71 & 0.23 \\
\hline $\begin{array}{l}\text { Sexuality Alcohol } \\
\text { Expectancies }\end{array}$ & 2.56 & 2.58 & 2.25 & 0.62 \\
\hline $\begin{array}{l}\text { Cognitive \& } \\
\text { Behavioral Impairment } \\
\text { Alcohol Expectancies }\end{array}$ & 2.75 & 3.0 & 2.57 & 0.49 \\
\hline $\begin{array}{l}\text { Risk and Aggression } \\
\text { Alcohol Expectancies }\end{array}$ & 2.69 & 2.74 & 2.62 & 0.20 \\
\hline $\begin{array}{l}\text { Self-Perception } \\
\text { Alcohol Expectancies }\end{array}$ & 1.72 & 1.65 & 1.58 & 0.22 \\
\hline $\begin{array}{l}\text { Risk of Sex with } \\
\text { Regular Partner }\end{array}$ & 2.54 & 2.24 & 3.19 & 0.52 \\
\hline $\begin{array}{l}\text { Risk of Sex with New } \\
\text { Partner }\end{array}$ & 5.18 & 5.43 & 5.40 & 0.21 \\
\hline $\begin{array}{l}\text { Benefits of Sex with } \\
\text { Regular Partner }\end{array}$ & 5.03 & 4.69 & 4.03 & 0.67 \\
\hline $\begin{array}{l}\text { Benefits of Sex with } \\
\text { New Partner } \\
\text { Conjunction }\end{array}$ & 2.20 & 2.04 & 1.54 & $\begin{array}{l}0.33 \\
0.000002\end{array}$ \\
\hline Variable & No Switch & $\begin{array}{l}\text { Switch to less } \\
\text { Risk Seeking in } \\
\text { Alcohol } \\
\text { Condition }\end{array}$ & $\begin{array}{l}\text { Switch to more } \\
\text { Risk Seeking in } \\
\text { Alcohol } \\
\text { Condition }\end{array}$ & Bayes Factor \\
\hline Negative Urgency & 2.08 & 2.11 & 2.05 & 0.20 \\
\hline Lack of Premeditation & 2.06 & 1.94 & 1.90 & 0.28 \\
\hline Lack of Perseverance & 1.96 & 1.98 & 2.11 & 0.23 \\
\hline Sensation Seeking & 3.26 & 3.14 & 2.87 & 0.50 \\
\hline Positive Urgency & 1.67 & 1.64 & 1.90 & 0.33 \\
\hline Sensitivity to Reward & 0.58 & 0.50 & 0.57 & 0.42 \\
\hline $\begin{array}{l}\text { Sensitivity to } \\
\text { Punishment }\end{array}$ & 0.36 & 0.34 & 0.35 & 0.20 \\
\hline Conjunction & & & & 0.0001 \\
\hline
\end{tabular}

Note. YAACQ = Young Adult Alcohol Consequences Questionnaire; AID = Alcoholimpaired Driving 


\section{References}

Adams, S., Attwood, A. S., \& Munafo, M. R. (2017). Drinking status but not acute alcohol consumption influences delay discounting. Human Psychopharmacology: Clinical and Experimental, 32, 1-6.

Aklin, W. M., Lejuez, C. W., Zvolensky, M. J., Kahler, C. W., \& Gwadz, M. (2005). Evaluation of behavioral measures of risk taking propensity with inner city adolescents. Behaviour Research and Therapy, 43(2), 215-228.

Amlung, M., MacKillop, J., Monti, P. M., \& Miranda, R. (2017). Elevated behavioral Economic demand for alcohol in a community sample of heavy drinking smokers. Journal of Studies on Alcohol and Drugs, 78, 623-628.

Amlung, M. McCarty, K. N., Morris, D. H., Tsai, C. L., \& McCarthy, D. M. (2015). Increased behavioral economic demand and craving for alcohol following a laboratory alcohol challenge. Addiction, 110, 1421-1428.

Amlung, M. T., Morris, D. H., \& McCarthy, D. M. (2014). Effects of acute alcohol tolerance on perceptions of danger and willingness to drive after drinking. Psychopharmacology, 231, 4271-4279.

Amlung, M., Morris, D. H., Hatz, L. E., Teeters, J. B., Murphy, J. G., \& McCarthy, D. M. (2016). Drinking-and-driving-related cognitions mediate the relationship between alcohol demand and alcohol-impaired driving. Journal of Studies on Alcohol and Drugs, 77, 656-660.

Arslan, R. C., Brummer, M., Dohmen, T., Dreweiles, J., Hertwig, R, \& Wagner, G. G. (2020). How people know their risk preference. Scientific Reports, 10(15365), 114. 
Aston, E. R., Metrik, J., \& MacKillop, J. (2015). Further validation of a marijuana purchase task. Drug and Alcohol Dependence, 152, 32-38.

Ávila, C., \& Parcet, M. A. (2002). Individual differences in reward sensitivity and attentional focus. Personality and Individual Differences, 33, 979-996.

Bechara, A., Damasio, A. R., Damasio, H., \& Anderson, S. W. (1994). Insensitivity to future consequences following damage to human prefrontal cortex. Cognition, 50, 7-15.

Berridge, K. C., \& Robinson, T. E. (2003). Parsing reward. TRENDS in Neurosciences, 26(9), 507-513.

Bidwell, L. C., MacKillop, J., Murphy, J. G., Grenga, A., Swift, R. M., McGeary, J. E. (2013). Biphasic effects of alcohol on delay and probability discounting. Experimental and Clinical Psychopharmacology, 21(3), 214-221.

Blais, A. \& Weber, E. U. (2006). A Domain-Specific Risk-Taking (DOSPERT) scale for adult populations. Judgment and Decision Making, 1(1), 33-47.

Brand, M., Roth-Bauer, M., Driessen, M., \& Markowitsch, H. J. (2008). Executive functions and risky decision-making in patients with opiate dependence. Drug and Alcohol Dependence, 97, 64-72.

Brevers, D., Bechara, A., Cleeremans, A., Kornreich, C., Verbanck, P., \& Noel, X. (2014). Impaired decision-making under risk in individuals with alcohol dependence. Alcoholism: Clinical and Experimental Research, 38(7), 1924-1931.

Bruner, N. R., \& Johnson, M. W. (2014). Demand curves for hypothetical cocaine in cocaine dependent individuals. Psychopharmacology, 231, 889-897.

Carlson, J. M., Foti, D., Mujica-Parodi, L. R., Harmon-Jones, E., \& Hajcak, G. (2011). 
Ventral striatal and medial prefrontal BOLD activation is correlated with reward related electrocortical activity: A combined ERP and fMRI study. Neuroimage, 57, $1608-1616$.

Charness, G., Garcia, T., Offerman, T. Villeval, M. C. (2020). Do measures of risk attitude in the laboratory predict behavior under risk in and outside of the laboratory? Journal of Risk and Uncertainty, 60, 99-123.

Christensen. C. J., Silberberg, A., Hursh, S. R., Roma, P. G., \& Riley, A. L. (2008). Demand for cocaine and food over time. Pharmacology, Biochemistry, and Behavior, 91, 209-216.

Coffey, S. F., Gudleski, G. D., Saladin, M. E., \& Brady, K. T. (2003). Impulsivity and rapid discounting of delayed hypothetical rewards in cocaine-dependent individuals. Experimental and Clinical Psychopharmacology, 11(1), 18-25.

Connor, B. T., Rham-Knigge, R. L., \& Jenkins, A. L. (2018). Revision and clarification of the sensitivity to punishment sensitivity to reward questionnaire. Personality and Individual Differences, 121, 31-40.

Corbin, W. R., Iwamoto, D. K., \& Fromme, K. (2011). A comprehensive longitudinal test of the acquired preparedness model for alcohol use and related problems. Journal of Studies on Alcohol and Drugs, 72(4), 602-610. PMCID: PMC3125884

Corr, P. J. (Ed.). (2008). The Reinforcement Sensitivity Theory of Personality. Cambridge University Press.

Dang, J., King, K. M., \& Inzlicht, M. (2020). Why are self-report and behavioral measures weakly correlated? Trends in Cognitive Science, 24(4), 267-269.

Davis, K. C., Hendershot, C. S., George, W. H., Norris, J., \& Heiman, J. R. (2007). 
Alcohol's effects on sexual decision making: An integration of alcohol myopia and individual differences. Journal of Studies on Alcohol and Drugs, 68, 843-851.

Davis-Stober, C. P., \& Brown, N. (2013). Evaluating decision maker "type" under p additive utility representations. Journal of Mathematical Psychology, 57(6), 320328.

Davis-Stober, C. P., McCarthy, D. M., Cavagnaro, D. R., Price, M., Brown, N., \& Park S. (2019). Is cognitive impairment related to violations of rationality? A laboratory alcohol intoxication study testing transitivity of preference. Decision, 6(2), 134144.

Deck, C., Lee, J., \& Reyes, J. (2014). Investing versus gambling: Experimental evidence of multi domain risk attitudes. Applied Economics Letters, 21(1), 19-23.

Doran, N., Khoddam, R., Sanders, P. E., Schweizer, C. A., Trim, R. S., \& Myers, M. G. (2013). A prospective study of the acquired preparedness model: The effects of impulsivity and expectancies on smoking initiation in college students. Psychology of Addictive Behaviors, 27(3), 714-722. PMCID: PMC4779050

Erskine-Shaw, M., Monk, R. L., Qureshi, A. W., \& Heim, D. (2017). The influence of groups and alcohol consumption on individual risk-taking. Drug and Alcohol Dependence, 179, 341- 346.

Fellner, G., \& Maciejovsky, B. (2002). Risk attitude and market behavior: Evidence from experimental asset markets. Journal of Economic Psychology, 28(3), 338-350.

Fillmore, M. T. (2003). Drug abuse as a problem of impaired control: Current approaches and findings. Behavioral and Cognitive Neuroscience Reviews, 2(3), 179-197.

Fishbein, D. H., Krupitsky, E., Flannery, B. A., Langevin, D. J., Bobashev, G., 
Verbitskaya, E., Augustine, C. B., Bolla, K. I., Zvartau, E., Scheech, B., Egorova, V., Bushara, N., \& Tsoy, M. (2007). Neurocognitive characterizations of Russian heroin addicts without a significant history of other drug use. Drug and Alcohol Dependence, 90, 25-38.

Franken, I. H. A., \& Muris, P., \& Georgieva, I. (2006). Gray’s model of personality and addiction. Addictive Behaviors, 31, 399-403.

Fromme, K., Stroot, E., \& Kaplan, D. (1993). Comprehensive effects of alcohol:

Development and psychometric assessment of a new expectancy questionnaire. Psychological Assessment, 5(1), 19-26.

Fujimoto, A., Tsurumi, K., Kawada, R., Takeuchi, H., Murai, T., \& Takahashi, H. (2017). Deficit of state-dependent risk attitude modulation in gambling disorder. Translational Psychiatry, 7(e1085), 1-6.

Gray, J. A. (1987). The psychology of fear and stress. Cambridge, England: Cambridge University Press.

Gray, J. C., \& MacKillop, J. (2015). Impulsive delayed reward discounting as a genetically influenced target for drug abuse prevention: A critical evaluation. Frontiers in Psychology, 6(1104), 1-13.

Hanson, K. L., Thayer, R. E., \& Tapert, S. F. (2014). Adolescent marijuana users have elevated risk-taking on the balloon analog risk task. Journal of Psychopharmacology, 28(11), 1080-1087.

Hatz, L. E., Park, S., McCarty, K. N., McCarthy, D. M., \& Davis-Stober, C. P. (2020). Young adults make rational sexual decisions. 20). Young adults make rational sexual decisions. Psychological Science, 31(8), 944-956. 
Hayaki, J., Herman, D. S., Hagerty, C. E., de Dios, M. A., Anderson, B. J., \& Stein, M. D. (2011). Expectancies and self-efficacy mediate the effects of impulsivity on marijuana use outcomes: An application of the acquired preparedness model. Addictive Behaviors, 36(4), 389-396. PMCID: PMC3039452

Heil. S. H., Johnson, M. W., Higgins, S. T., \& Bicketl, W. K. (2006). Delay discounting in currently using and currently abstinent cocaine-dependent outpatients and nondrug-using matched controls. Addictive Behaviors, 31, 1290-1294.

Hendershot, C., \& Stoner, S. (2007). Alcohol use, expectancies, and sexual sensation seeking as correlates of HIV risk behavior in heterosexual young adults. Psychology of Addictive Behaviors, 21(3), 365-372. PMCID: PMC2749924

Hoffman, W. F., Moore, M., Templin, R., McFarland, B., Hitzemann, R. J., \& Mitchell, S. H. (2006). Neurpsychological function and delay discounting in methamphetamine-dependent individuals. Psychopharmacology, 188, 162-170.

Johnson, M. W., Bickel, W. K., \& Baker, F. (2007). Moderate drug use and delay discounting: A comparison of heavy, light, and never smokers. Experimental and Clinical Psychopharmacology, 15(2), 187-194.

Johnson, P. S., \& Johnson, M. W. (2014). Investigation of "bath salts" use patterns within an online sample of users in the United States. Journal of Psychoactive Drugs, 46, 369-378.

Johnson, P. S., Sweeney, M. M., Hermann, E. S., \& Johnson, M. W. (2016). Alcohol increases delay and probability discounting of condom-protected sex: A novel vector for alcohol related HIV transmission. Alcoholism: Clinical and Experimental Research, 40(6), 1339-1350. 
Kahneman, D., \& Tversky, A. (1979). Prospect theory: An analysis of decision under risk. Econometrica: Journal of the Econometric Society, 47(2), 263-292.

Katz, E. C., Fromme, K., \& D’Amico, E. J. (2000). Effects of outcome expectancies and personality on young adults' illicit drug use, heavy drinking, and risky sexual behavior. Cognitive Therapy and Research, 24(1), 1-22.

Kellen, D., Mata, R., \& Davis-Stober, C. P. (2017). Individual classification of strong risk attitudes: An application across lottery types and age groups. Psychonomic Bulletin Review, 1-9.

Kirby, K. N., Petry, N. M., \& Bickel, W. K. (1999). Heroin addicts have higher discount rates for delayed rewards than non-drug-using controls. Journal of Experimental Psychology: General, 128(1), 78-87.

Koffarnus, M. N., \& Kaplan, B. A. (2018). Clinical models of decision making in addiction. Pharmacology, Biochemistry, and Behavior, 164, 71-83.

Lejuez, C. W., Read, J. P., Kahler, C. W., Richards, J. B., Ramsey, S. E., Stuart, G. L., Strong, D. R., Brown, R. A. (2002). Evaluation of a behavioral measure of risk taking: The Balloon Analogue Risk Task (BART). Journal of Experimental Psychology: Applied, 8(2), 75-84.

Lejuez, C. W., Simmons, B. L., Aklin, W. M., Daughters, S. B., \& Dvir, S. (2004). Risk taking propensity and risky sexual behavior of individuals in residential substance use treatment. Addictive Behaviors, 29(8), 1643-1647.

Luce, R. D. (2010). Interpersonal comparisons of utility for 2 of 3 types of people. Theory And Decision, 68, 5-24.

Lynam, D., Smith, G. T., Cyders, M. A., Fischer, S., \& Whiteside, S. (2007). The UPPS- 
P: A multidimensional measure of risk for impulsive behavior.

MacKillop, J., Miranda, R., Monti, P. M., Ray, L. A., Murphy, J. G., Rohsenow, D. J., McGeary, J. E., Swift, R. M., Tidey, J. W., \& Gwaltney, C. J. (2010). Alcohol demand, delayed reward discounting, and craving in relation to drinking and alcohol use disorders. Journal of Abnormal Psychology, 119(1), 106-114.

MacKillop, J., Murphy, J. G., Ray, L. A., Eisenberg, D. T. A., Lisman, S. A., Lum, J. K., \& Wilson, D. S. (2008). Further validation of a cigarette purchase task for assessing the relative reinforcing efficacy of nicotine in college smokers. Experimental and Clinical Psychopharmacology, 16(1), 57-65.

MacPherson, L., Magidson, J. F., Reynolds, E. K., Kahler, C. W., \& Lejuez, C. W. (2010). Changes in sensation seeking and risk-taking propensity predict increases in alcohol use among early adolescents. Alcoholism, Clinical and Experimental Research, 34(8), 1400-1408.

McCarthy, D. M., Kroll, L. S., \& Smith, G. T. (2001a). Integrating disinhibition and learning risk for alcohol use. Experimental and Clinical Psychopharmacology, 9, 389-398.

McCarthy, D. M., McCarty, K. N., Hatz, L. E., Prestigiacomo, C. P., Park, S., \& Davis Stober, C. P. (2020). Applying Bayesian cognitive models to decisions to drive after drinking. Addiction, 116(6), 1424-1430.

McCarthy, D. M., Miller, T. L., Smith, G. T., \& Smith, J. A. (2001b). Disinhibition and expectancy in risk for alcohol use: Comparing black and white college samples. Journal of Studies on Alcohol and Drugs, 62, 313-321.

McCarthy, D. M., Niculete, M. E., Treloar, H. R., Morris, D. H., \& Bartholow, B. D. 
(2012). Acute alcohol effects on impulsivity: Associations with drinking and driving behavior. Addiction, 107, 2109-2114.

McCarty, K. N. (2016). Evaluation of risk attitude as a predictor of substance related risk taking. [Master's thesis, University of Missouri-Columbia]. https://mospace.umsystem.edu/xmlui/bitstream/handle/10355/57599/research.pdf ?sequence $=2$

Morris, D. H., Treloar, H. R., Niculete, M. E., \& McCarthy, D. M. (2014). Perceived danger while intoxicated uniquely contributes to driving after drinking. Alcoholism: Clinical and Experimental Research, 38(2), 521-528.

Motschman, C. A., Hatz, L. E., McCarty, K. N., Merkle, E. C., Trull, T. J., \& McCarthy, D. M. (2020). Event-level predictors of alcohol-impaired driving intentions. Journal of Studies on Alcohol and Drugs, 81(5), 647-654.

Murphy, J. G., \& MacKillop, J. (2006). Relative reinforcing efficacy of alcohol among college student drinkers. Experimental and Clinical Psychopharmacology, 14(2), 219-227.

NIAAA. (2005). National Advisory Council on Alcohol Abuse and Alcoholism Recommended Council Guidelines on Ethyl Alcohol Administration in Human Experimentation.

O’Doherty, J., Kringelbach, M. L., Rolls, E. T., Hornak, J., \& Andrews, C. (2001). Abstract reward and punishment representations in the human orbitofrontal cortex. Nature Neuroscience, 4(1), 95-102.

Ortner, C. M., MacDonald, T. K., \& Olmstead, M. C. (2003). Alcohol intoxication reduces impulsivity in the delay-discounting paradigm. Alcohol \& Alcoholism, 38(2), 151- 
156.

Patterson, C. M., Newman, J. P. (1993). Reflectivity and learning from aversive events: toward a psychological mechanism for the syndromes of disinhibition. Psychological review, 100(4), 716-736.

Peacock, A., Bruno, R., Martin, F. H., \& Carr, A. (2013). The impact of alcohol and energy drink consumption on intoxication and risk-taking behavior. Alcoholism: Clinical And Experimental Research, 37(7), 1234-1242.

Peterson, M. (2009). An introduction to decision theory. Cambridge, UK: Cambridge University Press.

Petry, N. M., Bickel, W. K., \& Arnett, M. (1998). Shortened time horizons and insensitivity to future consequences in heroin addicts. Addiction, 93(5), 729-738.

Read, J., Kahler, C., Strong, D., \& Colder, C. (2006). Development and preliminary validation of the young adult alcohol consequences questionnaire. Journal of Studies on Alcohol and Drugs, 67, 169-177.

Reed, D. D., Kaplan, B. A., Becirevic, A. (2016). Basic research on the behavioral economics of reinforcer value. In: F. . DiGennaro Reed \& D. D. Reed (Eds.), Autism Service Delivery (pp. 279-306). Springer.

Reynolds, B., Richards, J. B., \& de Wit, H. (2006). Acute-alcohol effects of the Experiential Discounting Task (EDT) and a question-based measure of delay discounting. Pharmacology, Biochemistry, and Behavior, 83, 194-202.

Rose, A. K., Jones, A., Clarke, N., \& Christiansen, P. (2014). Alcohol-induced risk taking on the BART mediates alcohol priming. Psychopharmacology, 231, 2273-2280.

Rossow, I. (2008). Alcohol consumption and discounting. Addiction Research and Theory, 
$16(6), 572-584$.

SAMHSA. (2015). 2014 National Survey on Drug Use and Health (NSDUH). Table 2.41B Alcohol use in lifetime, past year, and past month among persons aged 18 or older, By demographic characteristics: Percentages, 2013 and 2014.

Settles, R. F., Cyders, M. A., \& Smith, G. T. (2010). Longitudinal validation of the acquired preparedness model of drinking risk. Psychology of Addictive Behaviors, 24(2), 198-208. PMCID: PMC2891564

Smith, G. T., \& Anderson, K.G. (2001). Adolescent risk for alcohol problems as acquired preparedness: A model and suggestions for intervention. In: P. M. Monti, S. M. Colby, \& T. A. O’Leary (Eds). Adolescents, Alcohol, and Substance Abuse: Reaching Teens Through Brief Interventions. (pp. 109-141). Guilford Press. Spurrier, M., \& Blaszczynski, A. (2014). Risk perception in gambling: A systematic review. Journal of Gambling Studies, 30, 253-276.

Szrek, H., Chao, L.-W., Ramlagan, S., \& Peltzer, K. (2012). Predicting (un) healthy behavior: A comparison of risk-taking propensity measures. Judgment and Decision Making, 7(6), 716-727. PMCID: PMC3846348

Van Ravenzwaaij, D., Dutilh, G., \& Wagenmakers, E. (2012). A diffusion model decomposition of the effects of alcohol on perceptual decision making. Psychopharmacology, 219, 1017-1025.

Verdejo-Garcia, A., Chong, T., T.-J., Stout, J. C., Yucel, M., \& London, E. D. (2018). Stages of dysfunctional decision-making in addiction. Psychopharmacology, Biochemistry, and Behavior, 164, 99-105.

Voas, R. B., Torres, P., Romano, E., \& Lacey, J. H. (2012). Alcohol-related risk of driver 
fatalities: An update using 2007 data. Journal of Studies on Alcohol and Drugs, 73(3), 341-50. PMCID: PMC3316710

Washio, Y., Higgins, S. T., Heil, S. H., McKerchar, T. L., Badger, G. J., Skelly, J. M., \& Dantona, R. L. (2011). Delay discounting is associated with treatment response among cocaine dependent outpatients. Experimental and Clinical Psychopharmacology, 19(3), 243-248.

Weafer, J., \& Fillmore, M. T. (2016). Low-dose alcohol effects on measures of inhibitory control, delay discounting, and risk-taking. Current Addiction Reports, 3(1), 75-84.

Wittwer, A., Hulka, L. M., Heinimann, H. R., Vonmoos, M., \& Quednow, B. B. (2016). Risky decisions in a lottery task are associated with an increase of cocaine use. Frontiers in Psychology, 7(640), 1-11.

Wray, T. B., Simons, J. S., \& Maisto, S. A. (2015). Effects of alcohol intoxication and Autonomic arousal on delay discounting and risky sex in young adult heterosexual men. Addictive Behaviors, 42, 9-13. 
VITA

Kayleigh McCarty was born in Tampa, Florida. She completed her undergraduate studies at the University of South Florida and received a Bachelor of Science degree in Biology, with a minor in Psychology in May 2012. She worked as a post-baccalaureate research assistant at the University of Maryland before starting graduate school in the Department of Psychological Sciences at the University of Missouri-Columbia in August 2013. Kayleigh received a Master of Arts degree in Psychology in July 2016. She completed her clinical internship at Warren Alpert Medical School of Brown University in June 2021 and received a Doctor of Philosophy degree in Clinical Psychology in July 2021. She will complete her postdoctoral training at the Center for Alcohol and Addiction Studies in the School of Public Health at Brown University. 